\title{
HUBUNGAN PANJANG LENGAN DAN KEKUATAN OTOT LENGAN DENGAN KECEPATAN PUKULAN GYAKU TSUKI
}

\section{RELATIONSHIP OF ARM LENGTH AND ARM MUSCLE STRENGTH WITH GYAKU TSUKI'S PUCKING SPEED}

\author{
Ruskin, Nurhayati Liputo \\ Jurusan Pendidikan Kepelatihan Olahraga, Fakultas Olahraga dan Kesehatan \\ Universitas Negeri Gorontalo \\ Kontak Penulis: liputonurhayati5@gmail.com
}

\begin{abstract}
ABSTRAK
Penelitian ini bermaksud mengetahui hubungan antara panjang lengan dan Kekuatan otot lengan dengan kecepatan pukulan Gyaku Tsuki pada atlet Pusat Pendidikan dan Latihan Pelajar (PPLP) Provinsi Gorontalo. Penelitian ini merupakan penelitian korelasi dengan teknik pengumpulan data menggunakan tes dan pengukuran. Populasi dan sampel merupakan seluruh atlet Pusat Pendidikan dan Latihan Pelajar (PPLP) Provinsi Gorontalo cabang olahraga Karate yang berjumlah 14 (empat belas) atlet. Instrumen penelitian pengukuran panjang lengan menggunakan meteran, kekuatan otot lengan menggunakan tes push up, dan kecepatan pukulan Gyaku Tsuki menggunakan tes 30 detik menggunakan samsak. Teknik analisis data menggunakan uji $\mathrm{t}$ dan uji $\mathrm{F}$. Temuan dalam penelitian ini menunjukkan bahwa ada hubungan yang signifikan antara panjang lengan dengan kecepatan pukulan Gyaku Tsuki dengan koefisiensi korelasi $\mathrm{t}_{\text {hitung }} 6,655>\mathrm{t}$ tabel 2,201, kemudian ada hubungan yang signifikan antara kekuatan otot lengan dengan kecepatan pukulan Gyaku Tsuki dengan koefisiensi korelasi $\mathrm{t}_{\text {hitung }}$ $4,44>\mathrm{t}_{\text {tabel }} 2,201$, kemudian diketahui bahwa ada hubungan panjang lengan dan kekuatan otot lengan dengan kecepatan pukulan Gyaku Tsuki dengan koefisien korelasi $\mathrm{F}_{\text {hitung }} 91.223>\mathrm{F}_{\text {tabel }}$ 3,89. Temuan dalam penelitian ini dapat dijadikan acuan pelatih dalam memilih atlet dan juga pemilihan latihan yang sesuai untuk pukulan Gyaku Tsuki.
\end{abstract}

Kata kunci: panjang lengan; kekuatan otot lengan; Gyaku Tsuki

\section{ABSTRACT}

This study intends to determine the relationship between arm length and arm muscle strength with the speed of Gyaku Tsuki's stroke on the athletes of the Student Education and Training Center (PPLP) Gorontalo Province. This research is a correlation research with data collection techniques using tests and measurements. The population and samples were all athletes of the Student Education and Training Center (PPLP) of Gorontalo Province in the Karate sport, totaling 14 (fourteen) athletes. The research instrument was measuring arm length using a meter, arm muscle strength using a push up test, and Gyaku Tsuki's hitting speed using a 30 second test using a bag. The data analysis technique used test and $F$ test. The findings in this study indicate that there is a significant relationship between arm length and speed of hitting Gyaku Tsuki with a correlation coefficient of t count 6,655 > t table 2,201, then there is a significant relationship between arm muscle strength and speed. Gyaku Tsuki 
punch with a correlation coefficient t count $4.44>t$ table 2.201 , then it is known that there is a relationship between arm length and arm muscle strength with Gyaku Tsuki punch speed with a correlation coefficient $F$ count $91.223>F$ table 3.89. The findings in this study can be used as a reference for coaches in selecting athletes and also selecting appropriate exercises for Gyaku Tsuki's strokes.

Keywords: sleeve length; arm muscle strength; Gyaku Tsuki

\section{PENDAHULUAN}

Sebelum Indonesia merdeka, istilah olahraga sering disebut sebagai latihan badan, latihan jasmani, gerak badan, sport atau olahraga, seperti pengertiannya saat ini. Peranan olahraga di Indonesia dalam perkembangan dan pertumbuhan di berikan pada sekolah-sekolah mulai taman kanak-kanak, Sekolah Dasar (SD), Sekolah Menengah Pertama (SMP), Sekolah Menengah Atas (SMA), atau bahkan Perguruan Tinggi (PT) serta masyarakat pada umumnya (Dai et al., 2021)(Fataha et al., 2021). Setiap tingkatan pendidikan pelajaran olahraga selalu di berikan, hal itu agar setiap siswa mempunyai kesegaran jasmani dan juga prestasi (Hidayat, 2019). Untuk prestasi sendiri mempunyai porsi pembinaan yang lebih spesifik daripada kebugaran jasmani, maka untuk prestasi diperlukan suatu tempat untuk seorang atlet mengembangkan keterampilan di bidang olahraga secara spesifik dengan cabang olahraga yang digelutinya.

Dewasa ini, di Indonesia sudah banyak wadah untuk pembinaan pembinaan siswa-siswa yang berbakat dalam suatu cabang olahraga. Salah satu wadah pembinaan tersebut adalah Pusat Pendidikan dan Latihan Pelajar (PPLP) (Henjilito, 2017). Sistem pembinaan di PPLP yaitu, atlet dibina untuk berprestasi dalam cabang olahraga yang ditekuni dan dididik dalam bidang akademis agar bisa menjamin masa depan (Harun et al., 2020). Pembinaan bidang akademis siswa PPLP dilakukan di sekolah-sekolah umum sesuai jenjang pendidikannya dan pembinaan prestasi olahraga dilakukan di bawah bimbingan pelatih PPLP sesuai dengan kecabangannya. Sehingga siswa-siswa yang berbakat tersebut akan dapat mengasah keterampilannya per cabang olahraga tanpa meninggalkan bangku sekolah.

Provinsi Gorontalo sendiri memiliki Pusat Pendidikan dan Latihan Pelajar (PPLP) yang berdiri pada tahun 2005 silam dan bernaung dibawah Dinas Pendidikan Pemuda dan Olahraga Provinsi Gorontalo, dimana didalamnya terdapat salah satu cabang olahraga yang dibina yakni cabang olahraga Karate. Karate merupakan olahraga bela diri yang mempunyai ciri khas yang dapat dibedakan dari jenis olahraga bela diri lainnya seperti Silat, Judo, Kung Fu, Kempo dan bela diri lainnya . Perbedaan ini dapat dilihat baik secara filosofi, teknik gerakan maupun atribut yang digunakan selama menjalani proses latihan dan pertandingan. Karate juga merupakan suatu cabang olahraga prestasi yang dipertandingkan baik di area nasional maupun internasional. Karate merupakan salah satu olahraga yang mempunyai karakteristik gerak dan teknik tersendiri, untuk itu harus dipelajari dan dilatih secara baik dan intensif.

Karate menjadi menarik dipelajari karena mengandung falsafah dan pembentukan karakter individu yang kuat, itu terlihat dari 5 sumpah Karate yaitu; 1) Sanggup memelihara kepribadian, 2) Sanggup patuh pada kejujuran, 3) Sanggup mempertinggi prestasi, 4) Sanggup 
menjaga sopan-santun, 5) Sanggup menguasai diri. Dalam sisi olahraga, karate merupakan bela diri yang sangat menarik ditonton karena menampilkan gerakan-gerakan yang efisien dan cepat (Kadir, 2020). Kelima sumpah tersebut haruslah dimiliki dan juga diamalkan oleh seorang Karateka.

Karate sendiri didalamnya dikembangkan teknik keterampilan pukulan dan tendangan hingga ke tingkat mahir yaitu tingkatan dimana seseorang dapat melakukan suatu gerak pukulan dan tendangan yang cepat dan tepat (Kadir, 2020). Untuk memiliki gerakan pukulan dan tendangan yang cepat dan tepat diperlukan latihan yang cukup lama. Salah satu pukulah dalam cabang olahraga Karate adalah pukulan Gyaku Tsuki yang merupakan pukulan dominan dilakukan seorang atlet Karate dalam kumite (perorangan) diantara pukulan Oi tsuki jodan dan Uraken (Matutu et al., 2019). Menurut peraturan WKF (World Karate Federation) 2012 pada saat ini kumite (pertarungan bebas) diperlukan kecepatan dan pukulan yang akurat ke daerah sasaran yang salah satunya adalah pukulan Gyaku Tsuki yang memperoleh nilai 1 yaitu (yuko) pukulan yang dilakukan dengan posisi tangan lurus memukul ke arah perut.

Pukulan Gyaku Tsuki merupakan pukulan lurus kearah ulu hati yang berlawanan dengan langkah kuda-kuda (Kadir \& Haryanto, 2021). Yang dapat diartikan bahwa semisalkan pukulan menggunakan tangan kanan, kaki sebelah kiri di depan dan juga kaki yang sebelah kanan berada di belakang. Maka pada pukulan tersebut memerlukan dukungan kuda-kuda yang kuat untuk menopang tubuh, panjang tangan untuk mencapai sasaran dan juga kekuatan otot tangan yang maksimal agar mendapatkan dampak pukulan yang diinginkan.

Hasil dari observasi peneliti yang dilakukan di Pusat Pendidikan dan Latihan Pelajar (PPLP) Gorontalo. ternyata gerakan yang dilakukan oleh atlet PPLP yang masih terdapat kesalahan dan belum memaksimalkan kondisi fisik pendukung dalam melakukan pukulan gyaku tsuki, masih banyak atlet saat melakukan pukulan Gyaku Tsuki pukulannya lambat di karenakan siswa kurang serius dalam melakukan pukulan dan masih ada beberapa siswa kekuatan pukulan tangan nya masih kurang kuat disebabkan kekuatan otot tangan nya terlihat lemah, dan juga jangkauan hasil pukulannya kurang maksimal pada saat memukul samsak. Hal tersebut secara langsung atau tidak langsung akan mempengaruhi hasil pukulan atlet.

Berdasarkan uraian di atas peneliti tertarik untuk meneliti hubungan panjang lengan dan kekuatan otot lengan dengan kecepatan pukulan Gyaku Tsuki pada atlet Pusat Pendidikan dan Latihan Pelajar (PPLP) Provinsi Gorontalo.

\section{METODE PENELITIAN}

Penelitian ini merupakan penelitian korelasi dengan teknik pengumpulan data menggunakan tes dan pengukuran. Populasi dalam penelitian ini adalah atlet Pusat Pendidikan dan Latihan Pelajar (PPLP) Provinsi Gorontalo cabang olahraga Karate yang berjumlah 14 (empat belas) atlet yang terdiri dari 6 (enam) atlet putra dan 8 (delapan atlet putri). Data yang perlu dikumpulkan ini menggunakan metode survei dengan teknik tes, pengambilan data dilakukan dengan pemberian tes dan pengukuran melalui metode survei, yaitu peneliti mengamati secara langsung pelaksanaan tes dan pengukuran di lapangan. Teknik analisis data menggunakan 
uji korelasi. Uji korelasi digunakan untuk mengetahui hubungan antara masing- masing variabel bebas terhadap variabel terikat menggunakan rumus person product moment.

\section{HASIL PENELITIAN}

Berdasarkan hasil tes pengukuran dapat diketahui sebagai berikut:

Tabel 1. Deskriptif Statistik

\begin{tabular}{lrrr}
\hline Statistik & $\begin{array}{c}\text { Panjang } \\
\text { Lengan }\end{array}$ & $\begin{array}{c}\text { Kekuatan } \\
\text { Otot Lengan }\end{array}$ & $\begin{array}{c}\text { Kecepatan } \\
\text { Pukulan }\end{array}$ \\
\hline$N$ & 14 & 14 & 14 \\
\hline Mean & 49.7143 & 16.2143 & 32.6429 \\
\hline Median & 49.0000 & 15.5000 & 33.0000 \\
\hline Mode & 47.00 & 14.00 & 35.00 \\
\hline SD & 2.64367 & 2.25929 & 2.09788 \\
\hline Minimum & 47.00 & 13.00 & 30.00 \\
\hline Maximum & 55.00 & 20.00 & 35.00 \\
\hline Sum & 696.00 & 227.00 & 457.00 \\
\hline
\end{tabular}

Sumber: Data Penelitian

Analisis data untuk menguji hipotesis memerlukan beberapa uji persyaratan yang harus dipenuhi agar hasilnya dapat dipertanggungjawabkan. Uji persyaratan analisis meliputi uji normalitas dan uji linieritas sebagai berikut:

Tabel 2. Uji Normalitas Data

\begin{tabular}{|c|c|c|c|}
\hline Variabel & $p$ & Sig. & Keterangan \\
\hline Panjang Lengan & 0.066 & \multirow[t]{3}{*}{0,05} & Normal \\
\hline Kekuatan Otot Lengan & 0.244 & & Normal \\
\hline Kecepatan Pukulan & 0.111 & & Normal \\
\hline
\end{tabular}

Sumber: Data Penelitian

Tabel 3. Uji Linieritas Data

\begin{tabular}{llll}
\hline $\begin{array}{c}\text { Hubungan } \\
\text { Fungsional }\end{array}$ & $\begin{array}{c}\text { Sig. Deviation } \\
\text { from linearity }\end{array}$ & Sig. & Keterangan \\
\hline $\mathrm{X} 1 . \mathrm{Y}$ & 0,19 & 0,05 & Linear \\
$\mathrm{X} 2 . \mathrm{Y}$ & 0,901 & & Linear \\
\hline
\end{tabular}

Sumber: Data Penelitian

Analisis data penelitian yang digunakan untuk menguji hipotesis terdiri atas analisis korelasi sederhana. Untuk memperjelas hubungan antara variabel bebas dengan variabel terikat maka dilakukan analisis regresi berganda, hasilnya sebagai berikut:

1. Hubungan Panjang Lengan dengan Kecepatan Pukulan Gyaku Tsuki

Uji hipotesis yang pertama adalah "ada hubungan panjang lengan dengan kecepatan pukulan Gyaku Tsuki". Hasil uji hipotesis dengan menggunakan analisis regresi uji t dapat dilihat pada tabel berikut ini. 
Tabel 3. Uji Linieritas Data Panjang Lengan dengan Kecepatan Pukulan Gyaku Tsuki

\begin{tabular}{lrrr}
\hline Korelasi & $\mathrm{t}_{\text {hitung }}$ & $\mathrm{t}_{\text {tabel }}$ & Keterangan \\
\hline $\mathrm{X} 1 . \mathrm{Y}$ & 6,655 & 2,201 & Signifikan \\
\hline
\end{tabular}

Sumber: Data Penelitian

Berdasarkan hasil analisis tersebut di atas diperoleh koefisien korelasi panjang lengan dengan kecepatan pukulan Gyaku Tsuki 6,655 bernilai positif, artinya semakin besar nilai yang mempengaruhi maka semakin besar nilai hasilnya. Uji keberartian koefisien korelasi

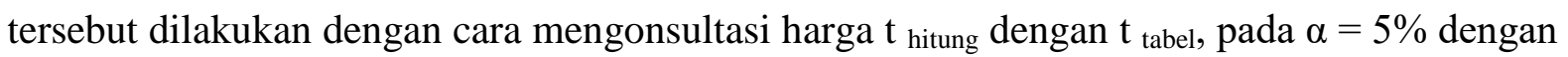
$\mathrm{N}=14$ diperoleh $\mathrm{t}_{\text {tabel }}$ sebesar 2,201. Karena koefisien korelasi antara $\mathrm{X1} . \mathrm{Y}=\mathrm{t}_{\text {hitung }} 6,655>$ $\mathrm{t}_{\text {tabel }}$ 2,201, berarti koefisien korelasi tersebut signifikan. Dengan demikian hipotesis yang berbunyi "ada hubungan panjang lengan dengan kecepatan pukulan Gyaku Tsuki", diterima. Artinya ada hubungan yang signifikan antara panjang lengan dengan kecepatan pukulan Gyaku Tsuki.

2. Hubungan Kekuatan Otot Lengan dengan Kecepatan Pukulan Gyaku Tsuki

Uji hipotesis yang kedua adalah "ada hubungan kekuatan otot lengan dengan kecepatan pukulan Gyaku Tsuki". Hasil uji hipotesis dengan menggunakan analisis regresi uji t dapat dilihat pada tabel berikut ini.

Tabel 4. Uji Linieritas Data Kekuatan Otot Lengan dengan Kecepatan Pukulan Gyaku Tsuki

\begin{tabular}{lccc}
\hline Korelasi & $\mathrm{t}_{\text {hitung }}$ & $\mathrm{t}_{\text {tabel }}$ & Keterangan \\
\hline $\mathrm{X} 2 . \mathrm{Y}$ & 4,44 & 2,201 & Signifikan \\
\hline \multicolumn{4}{l}{ Sumber: Data Penelitian }
\end{tabular}

Berdasarkan hasil analisis tersebut di atas diperoleh koefisien korelasi kekuatan otot lengan dengan kecepatan pukulan Gyaku Tsuki 4,44 bernilai positif, artinya semakin besar nilai yang mempengaruhi maka semakin besar nilai hasilnya. Uji keberartian koefisien korelasi tersebut dilakukan dengan cara mengonsultasi harga $\mathrm{t}_{\text {hitung }}$ dengan $\mathrm{t}$ tabel, pada $\alpha=$ $5 \%$ dengan $\mathrm{N}=14$ diperoleh $\mathrm{t}$ tabel sebesar 2,201. Karena koefisien korelasi antara $\mathrm{X} 2 . \mathrm{Y}=\mathrm{t}$ hitung 4,44>t tabel 2,201, berarti koefisien korelasi tersebut signifikan. Dengan demikian hipotesis yang berbunyi "ada hubungan kekuatan otot lengan dengan kecepatan pukulan Gyaku Tsuki", diterima. Artinya ada hubungan yang signifikan antara kekuatan otot lengan dengan kecepatan pukulan Gyaku Tsuki.

3. Hubungan Panjang Lengan dan Kekuatan Otot Lengan dengan Kecepatan Pukulan Gyaku Tsuki

Uji hipotesis yang ketiga adalah "ada hubungan panjang lengan dan kekuatan otot lengan dengan kecepatan pukulan Gyaku Tsuki". Hasil uji hipotesis dengan menggunakan analisis regresi uji $\mathrm{F}$ dapat dilihat pada tabel berikut ini.

Tabel 5. Uji Linieritas Data Bersama Kedua Variabel Independen 


\begin{tabular}{cccc}
\hline Korelasi & $\mathrm{F}_{\text {Hitung }}$ & $\mathrm{F}_{\text {Tabel }}$ & Keterangan \\
\hline $\mathrm{X} 1 . \mathrm{X} 2 . \mathrm{Y}$ & 91.223 & 3,89 & Signifikan \\
\hline
\end{tabular}

Sumber: Data Penelitian

Berdasarkan hasil analisis tersebut di atas diperoleh koefisien korelasi hubungan bersama panjang lengan dan kekuatan otot lengan dengan kecepatan pukulan Gyaku Tsuki menggunakan uji $\mathrm{F}$ sebesar 91.223 bernilai positif, artinya semakin besar nilai yang mempengaruhi maka semakin besar nilai hasilnya. Uji keberartian koefisien korelasi tersebut dilakukan dengan cara mengonsultasi harga $\mathrm{F}_{\text {hitung }}$ dengan $\mathrm{F}_{\text {tabel }}$, pada $\alpha=5 \%$ dengan $\mathrm{N}=14$ diperoleh $F_{\text {tabel }}$ sebesar 3,89. Karena koefisien korelasi antara X1.X2. $Y=F_{\text {hitung }} 91.223>F$ tabel 3,89, berarti koefisien korelasi tersebut signifikan. Dengan demikian hipotesis yang berbunyi "ada hubungan panjang lengan dan kekuatan otot lengan dengan kecepatan pukulan Gyaku Tsuki", diterima. Artinya ada hubungan yang signifikan antara panjang lengan dan kekuatan otot lengan dengan kecepatan pukulan Gyaku Tsuki.

\section{PEMBAHASAN}

Penelitian ini bertujuan untuk mengetahui hubungan antara panjang lengan dan power otot lengan dengan kecepatan pukulan Gyaku Tsuki di Pusat Pendidikan dan Latihan Pelajar (PPLP) Provinsi Gorontalo yang beralamat di Desa Pulubala, Kecamatan Kota Tengah, Kota Gorontalo, Provinsi Gorontalo. Hasil penelitian dijabarkan sebagai berikut:

1. Hubungan Panjang Lengan dengan Kecepatan Pukulan Gyaku Tsuki

Berdasarkan temuan dari penelitian menunjukkan bahwa ada hubungan yang signifikan antara panjang lengan dengan kecepatan pukulan Gyaku Tsuki di Pusat Pendidikan dan Latihan Pelajar (PPLP) Provinsi Gorontalo.

Panjang lengan merupakan faktor penunjang yang penting dalam kecepatan pukulan Gyaku Tsuki (Pranata et al., 2017). Lengan yang panjang mempunyai peranan untuk mencapai jangkauan sasaran yang diinginkan. Atlet Karate yang mempunyai lengan yang pendek akan mencapai jangkauan yang tidaklah luas daripada atlet yang mempunyai panjang lengan yang mumpuni panjangnya.

Dengan demikian dapat dikatakan panjang lengan merupakan variabel pendukung yang dapat diperkirakan keberhasilannya dalam pukulan Gyaku Tsuki. Sebagai anggota gerak atas, panjang lengan berfungsi dalam tangkisan maupun pukulan dalam olahraga bela diri Karate. Maka, pelatih haruslah memasukkan kriteria tersendiri dalam memilih atlet dengan pengukuran atropometri, supaya akan memperoleh atlet yang berkualitas. Hal ini disebabkan untuk panjang lengan sendiri merupakan bawaan dari lahir.

2. Hubungan Kekuatan Otot Lengan dengan Kecepatan Pukulan Gyaku Tsuki

Berdasarkan temuan dari penelitian menunjukkan bahwa ada hubungan yang signifikan antara kekuatan otot lengan dengan kecepatan pukulan Gyaku Tsuki di Pusat Pendidikan dan Latihan Pelajar (PPLP) Provinsi Gorontalo. 
Kekuatan otot lengan dalam garis besar untuk kebanyakan olahraga bela diri merupakan alat untuk menyerang lawan, menangkis serangan lawan, dan bias juga sebagai tumpuan tubuh (Amertha et al., 2020). Atlet Karate sendiri haruslah memiliki kekuatan otot tangan yang mumpuni untuk digunakan dalam teknik serangan maupun teknik bertahan, karena pada hakikatnya Karate merupakan olahraga bela diri dengan anggota tubuh sebagai alatnya.

Dengan demikian, wajar apabila kekuatan otot lengan merupakan sebuah hal yang penting dalam kecepatan pukulan Gyaku Tsuki. Hal ini karena tanpa kekuatan otot lengan, maka kecepatan pukulan Gyaku Tsuki tidak akan berarti apa-apa, sehingga power yang dihasilkan pun akan tidak memuaskan. Maka, pelatih pun harus pintar-pintar dalam memasukkan program untuk melatih kekuatan otot lengan tersebut agar tidak menjadi lemah.

3. Hubungan Panjang Lengan dan Kekuatan Otot Lengan dengan Kecepatan Pukulan Gyaku Tsuki

Berorientasi dari hasil temuan penelitian, ditemukan adanya hubungan yang signifikan antara panjang lengan dan kekuatan otot lengan dengan kecepatan pukulan Gyaku Tsuki di Pusat Pendidikan dan Latihan Pelajar (PPLP) Provinsi Gorontalo.

Secara khusus, setiap atlet pada cabang olahraga bela diri harus memiliki kemampuan dasar teknik yang baik yaitu kemampuan teknik memukul, menangkis, maupun memendang (Venkatraman et al., 2019). Akantetapi ada faktor-faktor fisik pula yang harus diperhatikan pelatih maupun atlet dalam latihan maupun pertandingan. Faktor fisik tersebut bisa berupa faktor bawaan atlet maupun faktor keseriusan atlet dalam berlatih. Faktor bawaan (panjang lengan) merupakan faktor penunjang yang efektif untuk menjangkau sasaran kearah lawan, terutama pukulan Gyaku Tsuki. Sedangkan faktor yang bias dilatihkan (kekuatan otot lengan) merupakan faktor yang dapat memberikan dampak yang maksimal dalam pukulan Gyaku Tsuki.

Apabila kedua faktor tersebut dikombinasikan dengan maksimal oleh pelatih maupun atlet untuk pukulan Gyaku Tsuki. Maka pukulan Gyaku Tsuki dari atlet tersebut akan bisa menjadi andalan dalam memperoleh poin pada setiap pertandingan. Pukulan tersebut akan menjadi cepat dengan jangkauan yang jauh, sehingga lawan tidak akan sempat menghindar dari pukulan.

\section{KESIMPULAN}

Berdasarkan hasil analisis data, deskripsi, pengujian hasil penelitian, dan pembahasan, dapat diambil kesimpulan bahwa:

Ada hubungan panjang lengan dengan kecepatan pukulan Gyaku Tsuki, dengan nilai t hitung 6,655 > t tabel 2,201. Ada hubungan kekuatan otot lengan dengan kecepatan pukulan Gyaku Tsuki, dengan nilai t hitung 4,44>t tabel 2,201. Ada hubungan panjang lengan dan kekuatan otot lengan dengan kecepatan pukulan Gyaku Tsuki, dengan nilai F hitung $91.223>\mathrm{F}$ tabel 3,89. Temuan dari penelitian ini mempunyai implikasi praktis bagi pihak-pihak yang terkait dengan bidang pelatihan olahraga, khususnya Karate, yaitu bagi pelatih ataupun atlet Karate 
yang akan meningkatkan kecepatan dalam pukulan Gyaku Tsuki, agar lebih memperhatikan kekuatan otot tangan. Hal ini karena kedua variabel ini mempunyai hubungan yang positif dan juga memberikan kontribusi yang nyata terhadap pukulan Gyaku Tsuki, sehingga dengan meningkatkan latihan kekuatan otot tangan akan secara otomatis pula akan meningkatkan pukulan Gyaku Tsuki.

\section{REFERENSI}

Amertha, P. A. S. U. W. A., Winaya, I. M. N., Wahyuni, N., \& Dinata, I. M. K. (2020). Hubungan Daya Ledak Lengan Dengan Kemampuan Pukulan Gyaku Tsuki Di Dojo Karate Di Denpasar. Majalah Ilmiah Fisioterapi Indonesia, 8(3). https://doi.org/10.24843/mifi.2020.v08.i03.p08

Dai, A., Hadjarati, H., \& Haryanto, A. I. (2021). Gaya resiprokal untuk meningkatkan keterampilan shooting bola basket. Altius: Jurnal Ilmu Olahraga Dan Kesehatan, 10(1), 53-65. https://doi.org/http://dx.doi.org/10.36706/altius.v10i1.14056

Fataha, I., Haryanto, A. I., Gani, A. A., Kadir, S. S., Samin, G., \& Ramadan, G. (2021). Contribution of Leg Muscle Power and Height to High Jump Results. JUARA: Jurnal Olahraga, 6(1). https://doi.org/10.33222/juara.v6i1.1247

Harun, H., Hidayat, S., \& Hadjarati, H. (2020). Analyze The Speed Of Side Kicks Of Teenage Fighters. Jambura Journal of Sports Coaching, 2(1). https://doi.org/10.37311/jjsc.v2i1.5627

Henjilito, R. (2017). Pengaruh Daya Ledak Otot Tungkai, Kecepatan Reaksi dan Motivasi terhadap Kecepatan Lari Jarak Pendek 100 Meter pada Atlet PPLP Provinsi Riau. Journal Sport Area. https://doi.org/10.25299/sportarea.2017.vol2(1).595

Hidayat, S. (2019). Kesegaran Jasmani Siswa 10-12 Tahun Se-Kota. Jambura Journal of Sports Coaching.

Kadir, S. (2020). Evaluation Of Vo2max Atlet Karate In The Covid-19 Pandemic Era. Jambura Journal of Sports Coaching. https://doi.org/10.37311/jjsc.v2i2.7058

Kadir, S., \& Haryanto, A. I. (2021). Development of the Gyaku Tsuki and Mawashi Geri Speed Test. COMPETITOR: Jurnal Pendidikan Kepelatihan Olahraga, 13(2). https://doi.org/10.26858/cjpko.v13i2.19059

Matutu, O. N., Nurliani, \& Fahrizal. (2019). Kontribusi Kecepatan Reaksi Tangan Dan Ketepatan Terhadap Kemampuan Pukulan Giaku Tsuki Pada Cabang Olahraga Karate Inkado Di Ranting Kota Makassar. Fakultas Ilmu Keolahragaan, Universitas Negeri Makassar.

Pranata, L. D., Yarmani, Y., \& Sugihartono, T. (2017). Pengaruh Latihan Beban Gaya-Pegas Karet Ban Terhadap Kecepatan Pukulan Kumite Gyaku Tzuki Untuk Atlet Karate Inkanas Kota Bengkulu. KINESTETIK, 1(2). https://doi.org/10.33369/jk.v1i2.3473

Venkatraman, J., Manwar, R., \& Avanaki, K. M. (2019). Development of a punch-o-meter for sport karate training. Electronics (Switzerland), $8(7)$. https://doi.org/10.3390/electronics8070782 